
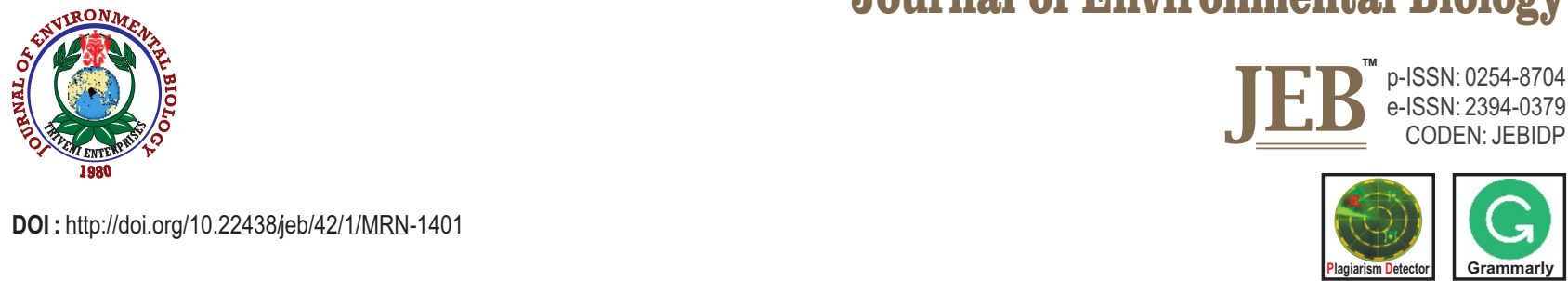

\title{
Biogenic synthesis of silver nanoparticles using Paenibacillus sp. in-vitro and their antibacterial, anticancer activity assessment against human colon tumour cell line
}

\author{
N. Sreenivasa*, B.P. Meghashyama, S.S. Pallavi, C. Bidhayak, A. Dattatraya, R. Muthuraj, K.N. Shashiraj, H. Halaswamy, S. \\ B. Dhanyakumara and M.D. Vaishnavi
}

P.G. Department of Studies in Botany, Karnatak University, Dharwad-580 003, India

*Corresponding Author Email : sreenivasanayaka06@gmail.com

\section{Abstract}

Aim: To evaluate the antibacterial and anticancer activities of silver nanoparticles (AgNPs) synthesized from aqueous extract of Paenibacillus sp. strain NS-36.

Methodology: The green synthesized AgNPs were characterized by UV-Vis. spectroscopy, Fourier Transform Infrared Spectroscopy, Atomic Force Microscopy, X-Ray Diffraction, Scanning Electron Microscopy, Energy Dispersive X-ray Spectroscopy, and Transmission Electron Microscopy. Antibacterial activity was assessed against pathogenic bacteria by using agar well diffusion method and the anticancer activity was evaluated against Human Colon Tumour116 cell line using 96 well plate cell proliferation assay.

Results: The synthesized AgNPs showed UV-Vis absorbance peak at $416 \mathrm{~nm}$. The characterization analyses revealed the shape as spherical and size ranging from 17.49 to $52.85 \mathrm{~nm}$ and the presence of

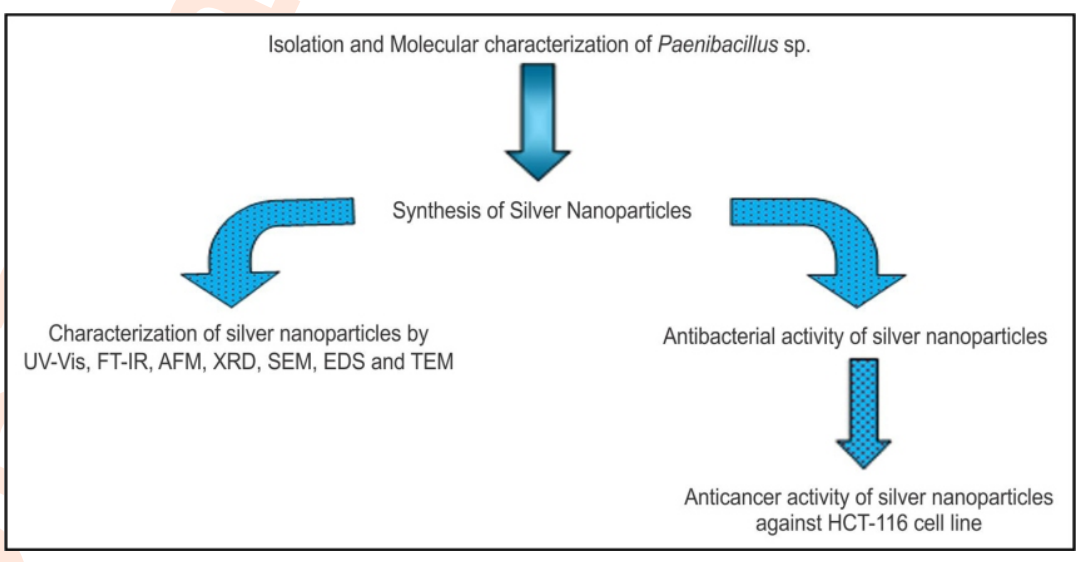
different functional groups and elements that involved in the stabilization and capping. The antibacterial activity revealed that AgNPs have good inhibitory action on pathogens, whereas the results of anticancerous assessment indicated that AgNPs have a dose-dependent activity on the Human Colon Tumour- 116 cancer cells and the $\mathrm{IC}_{50}$ value was found to be $81.45 \mu \mathrm{g} \mathrm{ml}^{-1}$.

Interpretation: The AgNPs exhibited considerable antibacterial activity against bacterial pathogens by rupturing and damaging the cell membrane. The AgNPs release silver ions into the cell once they attached to the cell membrane and disrupt the bacterial DNA replication. The AgNPs are toxic to tumour cells and induce intracellular reactive oxygen species which damage cells. Along with ROS, the rounding and shrinkage of tumour cells caused by AgNPs reduced the $\%$ viability of cancer cells.

Key words: Antimicrobial activity, Cytotoxicity, Paenibacillus sp, Silver nanoparticles, Tumour cells

How to cite : Sreenivasa, N., B.P. Meghashyama, S.S. Pallavi, C. Bidhayak, A. Dattatraya, R. Muthuraj, K.N. Shashiraj, H. Halaswamy, S. B. Dhanyakumara and M.D. Vaishnavi: Biogenic synthesis of silver nanoparticles using Paenibacillus sp. in-vitro and their antibacterial, anticancer activity assessment against human colon tumour cell line. J. Environ. Biol., 42, 118-127 (2021). 


\section{Introduction}

Nanoparticles exhibit completely new or improved properties due to their small size and large surface to volume ratio. Nanoparticles can be synthesized from various metals, such as gold, silver, copper, magnesium, zinc, titanium, chromium, etc. (Nayak et al., 2020). However, silver nanoparticles (AgNPs) are of particular interest due to their specific properties and wide applications in different fields, such as bio-sensing, imaging, drug delivery, medicine, etc. (Ahmad et al., 2007; Ali et al., 2018). There are different methods for synthesizing nanoparticles, like chemical, physical and biological methods. The physical and chemical methods used for the synthesis of AgNPs are marked as harmful to the environment as they release a large amount of toxic and hazardous by-products (Singh et al., 2018). Among them, the biological or green synthesis method of nanotechnology is considered to be the easier, comparatively inexpensive and environmentally friendly, however, the synthesis of AgNPs using biological entities, for instance, plant parts, bacteria, fungi, actinomycetes, cyanobacteria and algae are gaining interest (Mouxing et al., 2006; Ahmed and Mustafa, 2019).

Microorganisms produce various enzymes that are industrially important and the culture supernatant contains reductase enzyme responsible for the synthesis of nanoparticles. Among the microbial synthesis methodologies; bacteria have received great attention because of rapid growth, easy handling and genetic modification (Akter and Huq, 2020). Some inorganic materials are produced extracellular or intracellular by bacteria and in some silver resistant bacteria, ionic silver can accumulate on the cell wall as much as $25 \%$ in case of dry weight biomass. The extracellular method of nanoparticle synthesis using various microorganisms is considered as an easy method, although large-scale production of AgNPs requires optimum temperature, $\mathrm{pH}$, incubation period and exact amount of oxidant and reductant (Deepika et al., 2013; Ameen et al., 2019).

Some studies have indicated that the AgNPs can be synthesized by using the culture supernatants of bacteria, especially the mesophiles and there is a need to extend the search for microbes, such as thermophiles and psychrophiles from different environments. In the external environment of a cell, the precipitation of nanoparticles occurs due to metabolic activities of microorganisms (Sadowski et al., 2008; Shivaji et al., 2011; Ameen et al., 2019). Soil is a good source of microbial diversity and these microbes can be used for human welfare. Soil bacteria also need inexpensive and less nutrient media for growth that makes them a perfect candidate for utilization (Amdadul, 2020). Green nanotechnology-based AgNPs are characterized by low toxicity to humans and high bactericidal potential.

The AgNPs have a high surface area to volume ratio that makes them an important antimicrobial agent against a wide range of microorganisms, including multidrug-resistant bacterial pathogens (Hamouda et al., 2019). The unique physico-chemical properties and biofunctional features, such as antibacterial, antifungal, antiviral, antiplatelet, anti-angiogenesis, and antiinflammatory activities of AgNPs play an important role in development and implementation of novel biomedical strategies (Roy et al., 2019). Recently, the AgNPs have gained much importance as promising anticancer drugs by triggering apoptotic mechanisms against various human cancer cell lines (Burdusel et al., 2018; Ahmed et al., 2019). Cancer is considered as one of the leading causes of mortality due to the fact that it causes one out of six deaths worldwide annually (Bray et al., 2018). In recent years, nanotechnology-based cancer diagnosis and therapy methods are gaining attraction in the medical field and has unfolded a newer horizon of interdisciplinary areas like, chemistry, medicine, engineering and biology. AgNPs can induce cytotoxicity in tumour cells by altering the cell morphology, inducing oxidative stress, and reducing cell viability in various kinds of cancers (Bhatnagar et al., 2019; Gnanakani et al., 2019; Ratan et al., 2020). Nanomedicine is a promising area that can induce changes affecting cancer treatment protocols, and the green synthesized AgNPs are effective anticancer mediators used for detection, prevention and bioremediation of tumour cells. AgNPs are intimately investigated for their promising anticancer property exhibited against different human cancer cell lines, like IMR-90, MCF-7, U251, MDA-MB-231, HT-29, HeLa, A-549 and HepG2 tumour cells (Burdusel et al., 2018; Burlacu et al., 2019; Nayaka et al., 2020; Rajoka et al., 2020).

Paenibacillus sp. strain NS-36 is a Gram-positive, aerobic, endospore-forming, rod-shaped and motile bacterium with $51 \%$ Guanine+Cytosine content. It belongs to family Paenibacillaceae and class Bacilli. The bacterium is a mesophile and can grow in the temperature range of 10 to $37^{\circ} \mathrm{C}$ with $\mathrm{pH}$ ranging from 5.0 to 9.0. The members of genus Paenibacillus can be detected in rhizosphere soil and vegetable matters (Piuri et al., 1998; Girardin et al., 2002; Von-der et al., 2003). The antimicrobial activities of some Paenibacillus sp. have been reported and the results have proved that the species of genus Paenibacillus possess good antimicrobial activities against many pathogenic Gram-positive and Gram-negative bacteria, including some fungi (Aw et al., 2016; Huang et al., 2017; Pajor et al., 2020; Zhang et al., 2020). Keeping in view the in-vitro antimicrobial studies of different species of Paenibacillus, the present investigation aimed to study the antimicrobial activity and potential anticancer activity of synthesized AgNPs from the isolated bacterium Paenibacillus sp. strain NS-36.

\section{Materials and Methods}

Isolation of bacterial strains: In the present study, the soil samples were collected from in and around Karnatak University Campus, Dharwad, Karnataka, India, during February 2019. The samples were serial diluted up to $10^{-5}$ dilution and inoculated on Nutrient agar medium. The culture plates were incubated at $35^{\circ} \mathrm{C}$ for $48 \mathrm{hr}$ and a total of 38 aerobic bacterial strains were isolated (Holt et al., 1994). From these 38 isolated strains, a single bacterium was selected based on its unique morphological 
growth features, like colonial pattern forming and the selected bacterium was designated as strain NS-36.

Genotypic characterization of isolate: The genomic DNA was extracted from fresh culture of NS-36 strain using Hi-PurA bacterial DNA purification kit according to manufacturer's instructions. The $16 \mathrm{~S}$ rRNA gene was PCR amplified using two universal primers, bacterial-domain-specific primer $8 \mathrm{~F}$ and prokaryote-specific primer 1490R (Sekiguchi et al., 1998). Purified PCR amplicons were sequenced (Sanger Sequencing 3500 Series, Genetic Analyzer) and deposited to the NCBI database via nucleotide BLAST web portal. The DNA sequences were selected based on similarity to construct a phylogenetic tree as per the standard procedure by using the MEGA 7.0 software (Tamura et al., 2015).

Preparation of cell-free extract: The NS-36 strain was inoculated into sterile nutrient broth in a $250 \mathrm{ml}$ Erlenmeyer flask. The culture flasks were incubated on a rotating shaker set at a speed of $200 \mathrm{rpm}$ for $48 \mathrm{hr}$ at room temperature. After incubation, the broth containing strain NS-36 culture was centrifuged at $12,000 \mathrm{rpm}$ (REMI R-24) for $10 \mathrm{~min}$ to obtain cell-free supernatant.

Biosynthesis of AgNPs: The cell-free supernatant of NS-36 strain $(80 \mathrm{ml})$ was mixed with an aqueous solution of $0.1 \mathrm{mM}$ silver nitrate. The $\mathrm{pH}$ was adjusted to 8.5 and the mixture was incubated in dark for 5 days. Reduction of silver ion was examined by change in colour of the solution at different time intervals.

\section{Characterizations of AgNPs}

UV-visible spectroscopy: The test solution was taken in a cuvette (quartz) and analyzed for optical density from 300 to 700 $\mathrm{nm}$ wavelength using an UV-Vis. spectrophotometer (Double beam spectrophotometer, METASHUV-9000A).

Fourier Transform Infrared Spectroscopy: FT-IR spectroscopy was performed using FT-IR spectrophotometer (Nicolet 6700, Thermo Fisher Scientific, Waltham, Massachusetts, USA). The pellets were prepared by mixing AgNPs dry powder with $\mathrm{KBr}$ and scanned in the range of 4000 to $400 \mathrm{~cm}^{-1}$ at a resolution of $4 \mathrm{~cm}^{-1}$ in transmittance mode.

X-ray Diffraction: The particle size and crystal structure of synthesized nanoparticles was studied by XRD (Rigaku, Smartlab SE) instrument (CuKa radiation, $\lambda=0.15418 \mathrm{~nm}$ ) running at $40 \mathrm{kV}$ and $30 \mathrm{~mA}$. The sample was prepared by making a smooth surface of AgNPs powder on the sample holder and diffracted intensities were recorded from 30.010 to 79.990 of $2 \theta$ angles. The crystalline size was calculated from FWHM of diffraction peaks of XRD pattern with the help of Debye-Scherrer equation.

Atomic Force Microscopy: Morphology and size of AgNPs were ascertained by atomic force microscopy (Nano Surf Flex AFM).
The sample was prepared by spin coating the AgNPs solution onto the glass slide and the slide was dried at room temperature and subjected to AFM analysis.

Scanning Electron Microscopy and Energy Dispersive X-ray analysis: The surface images and concentration of metal ions were obtained using Energy dispersive X-ray coupled with scanning electron microscope (JSM-IT 500). The chemical state and composition of the elements present in the AgNPs were examined using gold-coated AgNPs onto the sample holder.

Transmission Electron Microscopy: The surface morphology and size of AgNPs were analysed by TEM (Hitachi, Model: S$3400 \mathrm{~N}$ ) at an accelerating voltage of $80 \mathrm{kV}$. The particle size and surface morphology of nanoparticles were evaluated using Image J1.45s software.

Antibacterial assay: The antagonistic activity of biosynthesized AgNPs was tested against four pathogenic bacteria, namely Staphylococcus aureus (MTCC6908), Enterococcus faecalis (MTCC6845), Streptococcus pneumoniae (MTCC2672) and Escherichia coli (MTCC40) by agar well diffusion technique, in which $6 \mathrm{~mm}$ wells were cut in nutrient agar medium by swabbing the pathogens uniformly in each plate using cotton swabs. The working solution was prepared by making a suspension of $1 \mathrm{mg}$ AgNPs in $1 \mathrm{ml}$ distilled water. Later, $25 \mu \mathrm{l}, 50 \mu \mathrm{l}, 75 \mu \mathrm{l}$ and $100 \mu \mathrm{l}$ of AgNPs suspension was pipetted into each well and incubated at $37{ }^{\circ} \mathrm{C}$ overnight. After incubation period, the diameter of inhibition zone around each well was measured and expressed in millimeters.

Anticancer activity: MTT assay is used for the determination of cytotoxicity and cell proliferation, based on the reduction of yellow-coloured water-soluble tetrazolium dye MTT to formazan crystals. Human Colon Tumor (HCT-116) cells were procured from NCCS, Pune and subcultured and incubated at $37{ }^{\circ} \mathrm{C}$ in $5 \%$ $\mathrm{CO}_{2}$ incubator before analysis. The cells were plated in 96 well plates (Thermoscientific Nunc, Cat.No.167008) at a required cell density of 20,000 cells per well without the test agent. Appropriate

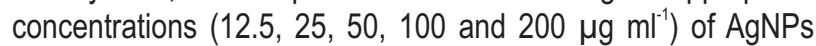
suspension in DMSO was added in each well, excluding the wells with $15 \mu \mathrm{M}$ Camptothecin drug as positive control and the well with only medium and cells as negative control. The cells were incubated for $24 \mathrm{hr}$, the MTT reagent to a final concentration of 0.5 $\mathrm{mg} \mathrm{ml}^{-1}$ of total volume was also added. The plates were incubated for $24 \mathrm{hr}$ at $37^{\circ} \mathrm{C}$ in $5 \% \mathrm{CO}_{2}$ atmosphere and then the MTT reagent was removed and $100 \mu$ l of solubilisation solution (DMSO) was added. The number of viable cells was determined by recording the absorbance at $570 \mathrm{~nm}$ on ELISA reader at 630 $\mathrm{nm}$ wavelength.

\section{Results and Discussion}

Among 38 bacterial isolates, the strain NS-36 was selected and further used for the synthesis of AgNPs. The Erlenmeyer flask with bacterial cell-free supernatant was pale 


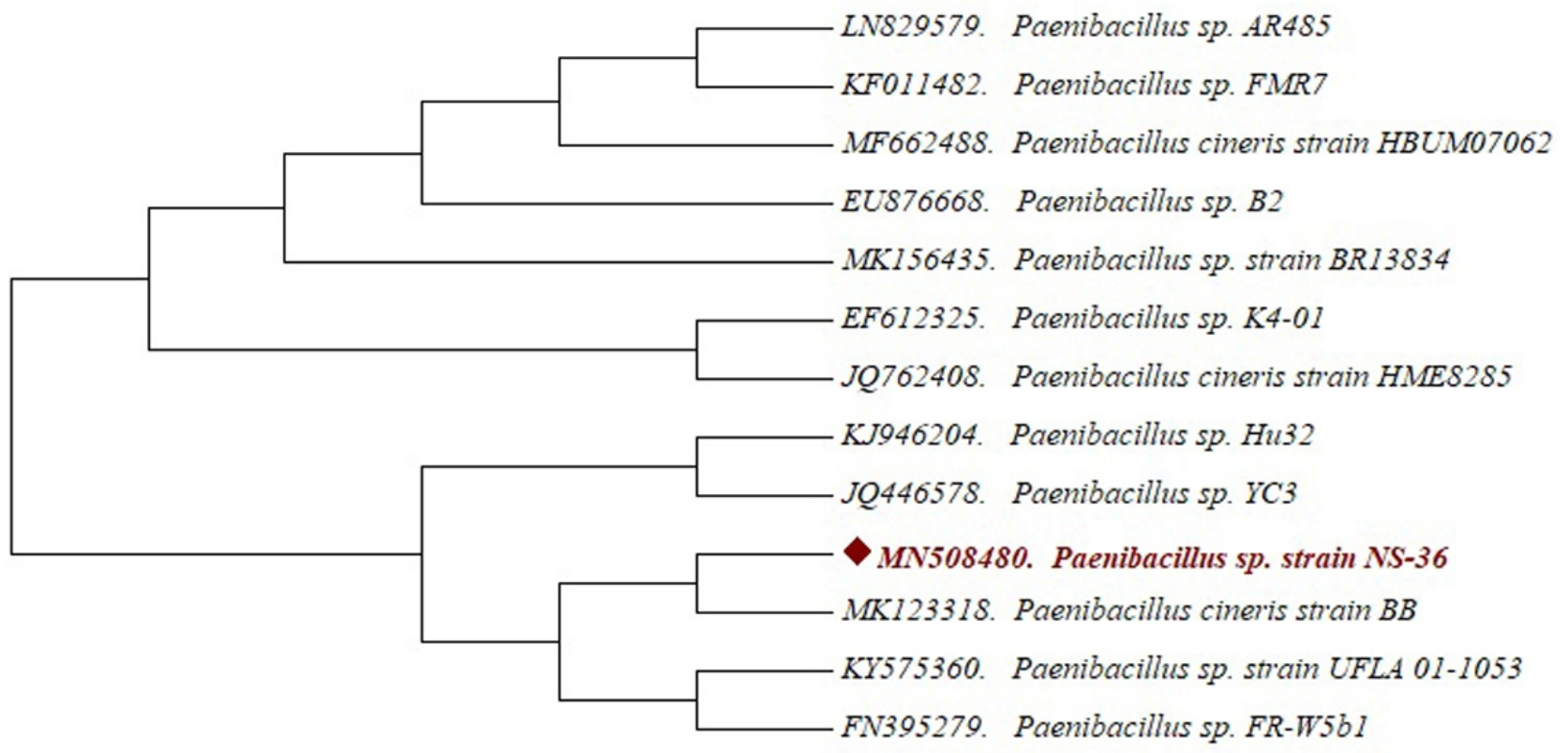

Fig. 1: Phylogenetic tree of the isolate Paenibacillus sp. NS-36.

yellow prior to silver nitrate addition, however, the colour changed from pale yellow to brown at the end of incubation period. The appearance of brown colour was a clear indication of the formation of $\mathrm{AgNPs}$ due to reduction of $\mathrm{Ag}^{+}$ions to $\mathrm{Ag}^{0}$ (elemental state) by the reducing agents present in the cultural supernatant. Similar results about the colour change of the reaction mixture after addition of $\mathrm{AgNO}_{3}$ followed by incubation in dark condition have been reported and also suggests that microorganism extract containing various secondary metabolites may act both as reducing and capping agent in AgNPs synthesis (Kalishwarlal et al., 2010; Gnanakani et al., 2019; Priya et al., 2020).

The genomic DNA was extracted and 1554 base pairs of 16S rRNA gene sequence were submitted to the NCBI database (Accession Number: MN508480). The sequence was initially characterized by nucleotide BLAST analysis, which hit 100 homologous 16S rRNA genes from various species. Most homologies of sequence were found with $16 \mathrm{~S}$ rRNA gene sequence of the strain NS-36 and it shared $98.36 \%$ similarity with Paenibacillus cineris strain BB (Accession Number: MK123318). A phylogenetic tree was constructed with a complete gene sequence and manifested in Fig. 1. Similar reports have been documented by Meenal et al. (2012) and Aw et al. (2016), where a marine and a soil bacteria were identified as Idiomarina sp. PR588 and Paenibacillus tyrfis MSt1T, based on nucleotide homology and phylogenetic tree analysis. The UV-Vis. absorption spectrum of AgNPs synthesized by the strain NS-36 (Fig. 2A) indicated a strong surface plasmon resonance (SPR) maximum at $416 \mathrm{~nm}$ as a characteristic peak for AgNPs. The increase in the intensity of SPR peak could be due to the increasing number of nanoparticles formed as a result of reduction of $\mathrm{Ag}^{+}$ions present in the aqueous extract. The surface plasmon band in the AgNPs aqueous solution remain between 410 to $430 \mathrm{~nm}$ throughout the reaction period, indicating the particles are dispersed with no evidence for aggregation (Ahmad et al., 2007; Karthik et al., 2012; Allam et al., 2019). FT-IR spectrum showed bio-fabrication of AgNPs mediated by cell-free supernatant of NS-36 strain, when scanned from 4000 to $400 \mathrm{~cm}^{-1}$ (Fig. 2B). The intense bands at 3360, 2926 $\mathrm{cm}^{-1}$ were a characteristic group of $\mathrm{C}-\mathrm{H}$ stretching alkenes, 2369 and $2342 \mathrm{~cm}^{-1}$ corresponded to $\mathrm{P}-\mathrm{H}$ stretching phosphine and $1651 \mathrm{~cm}^{-1}$ was identified as $\mathrm{C}=\mathrm{C}$ alkenes. The peak at $1568 \mathrm{~cm}^{-1}$ was identified as carboxylic acid and at $1416 \mathrm{~cm}^{-1}$ corresponded to $\mathrm{C}-\mathrm{C}$ aromatic compounds.

The peak of $1304 \mathrm{~cm}^{-1}$ assigned to $\mathrm{N}-\mathrm{O}$ aliphatic nitro compounds, whereas the peak of $1270 \mathrm{~cm}^{-1}$ and $1149 \mathrm{~cm}^{-1}$ were assigned to the stretching of $\mathrm{C}-\mathrm{O}$ alkyl ether and $\mathrm{P}-\mathrm{H}$ bending phosphine. The peak of $1108 \mathrm{~cm}^{-1}$ and $1033 \mathrm{~cm}^{-1}$ corresponded to $\mathrm{C}-\mathrm{N}$ amines and $\mathrm{S}=\mathrm{O}$ sulphoxide or carboxylic acid. The peak of $668 \mathrm{~cm}^{-1}$ and $650 \mathrm{~cm}^{-1}$ attributed to the stretching of C-Br and C-H bending alkenes. Secondary metabolites, such as terpenoids, flavonoids, alkaloids, phenolics, proteins, carbohydrates, lipids and peptides present in the supernatant are also involved in capping and stabilization of AgNPs (Srivastava et al., 2012; Yurtluk et al., 2018; Gnanakani et al., 2019). The phase purity and composition of AgNPs and the crystalline nature were examined by XRD. The XRD spectrum (Fig. 2C) showed four distinct diffraction peaks at $31.87^{\circ}, 45.58^{\circ}, 64.62^{\circ}$ and $77.51^{\circ}$ corresponding lattice plane value was indexed at (111), (200), (220) and (311) planes of face-centred cubic silver with a lattice 

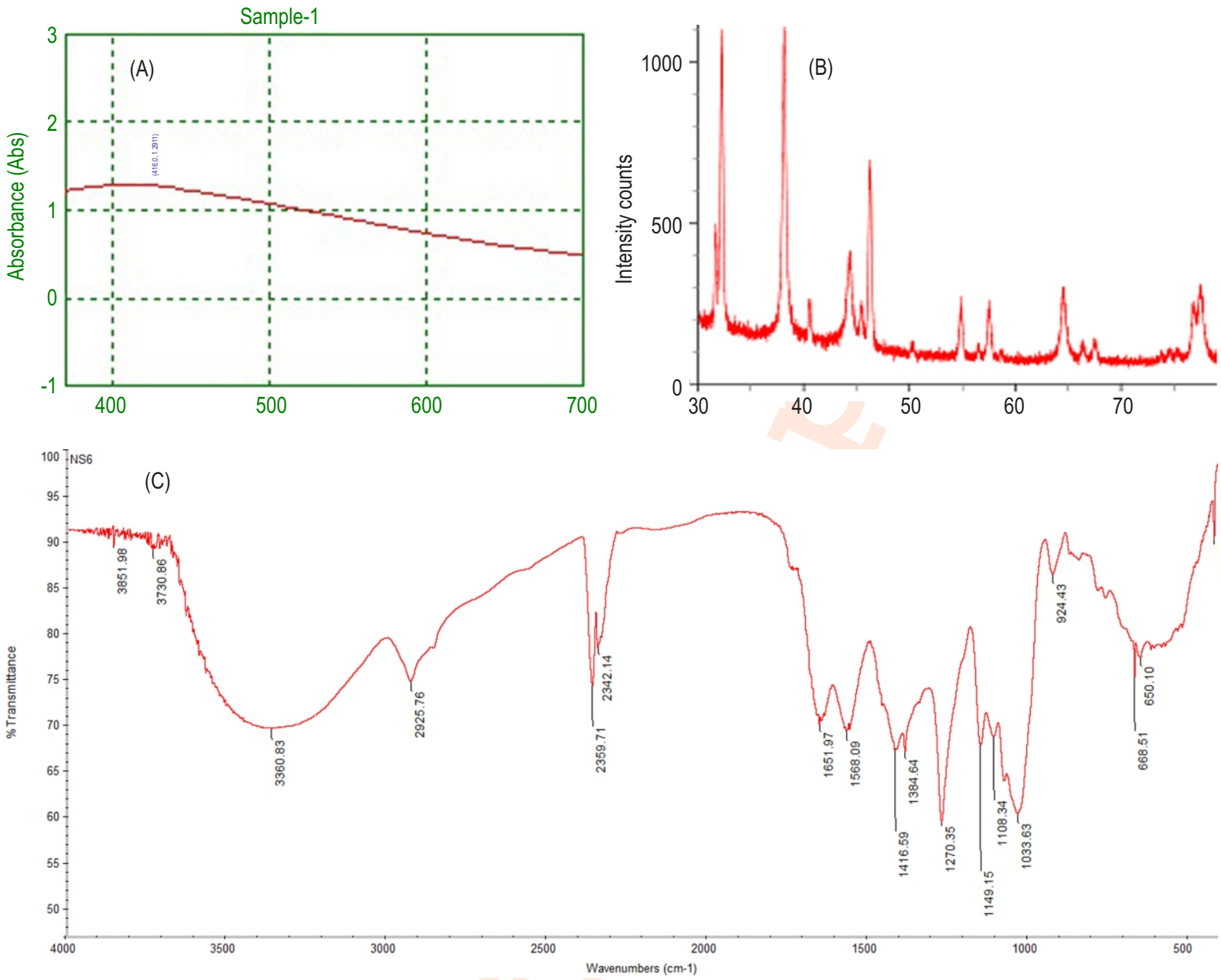

Fig. 2: Characterization of Panibacillus sp. NS-36 mediated AgNPs (A) UV-Vis spectra of NS-36 AgNPs; (B) XRD pattern of NS-36 AgNPs, and (C) FTIR spectrum of NS-36 AgNPs.

parameter of $a=4.08 \mathrm{~A}^{0}$. The average particle size estimated was approximately $27.48 \mathrm{~nm}$. Similarly, Gurunathan et al. (2009) and Meenal et al. (2012) reported the size of AgNPs synthesized from bacterial extracts between 20 to $50 \mathrm{~nm}$. In another report, the characteristic Bragg reflection peaks of $\mathrm{Ag}$ crystallites were observed at (111), (200), (220) and (311) with an average size of $49.5 \mathrm{~nm}$ (Hossain et al., 2019).

A two-dimensional horizontal cross-section of AgNPs indicated that the nanoparticles were well defined, spherical and poly-dispersed. The three-dimensional image showed the surface morphology and homogeneity in the distribution of nanoparticles. The AFM data revealed that the size of AgNPs ranged from $17.49 \mathrm{~nm}$ to $52.85 \mathrm{~nm}$ (Fig. $3 \mathrm{~A}$ and $3 \mathrm{~B}$ ) with a distance of $39.06 \mathrm{~nm}$ from each other (Fig. 3C). These observations can be correlated with previous studies, where synthesized AgNPs were spherical and their size ranged between
13 to $75 \mathrm{~nm}$, poly-dispersed, and some of them were agglomerated (Saravanan et al., 2018; Sowmya et al., 2019). SEM images showed that most of the AgNPs were predominantly spherical having a smooth surface and well dispersed with a close compact arrangement (Fig. 4A). The EDX spectrum of synthesized nanoparticles suggested the presence of silver as the major ingredient element. AgNPs gave a strong signal peak at $3 \mathrm{keV}$ and the quantitative information of biosynthesized AgNPs with the presence of various elements was reported (Fig. 4B). This corroborates the study of Nadhe et al. (2019), who identified the presence of AgNPs on the EDX spectrum, while their morphology was studied by SEM. In other reports, the SEM images showed polydispersive nature of AgNPs and the EDX spectrum showed the peak in the silver region at $3 \mathrm{keV}$, which is typical for metallic silver nanocrystals due to surface plasmon resonance (Nayaka et al., 2020; Priya et al., 2020). Transmission electron microscopic images of AgNPs synthesized from the NS- 


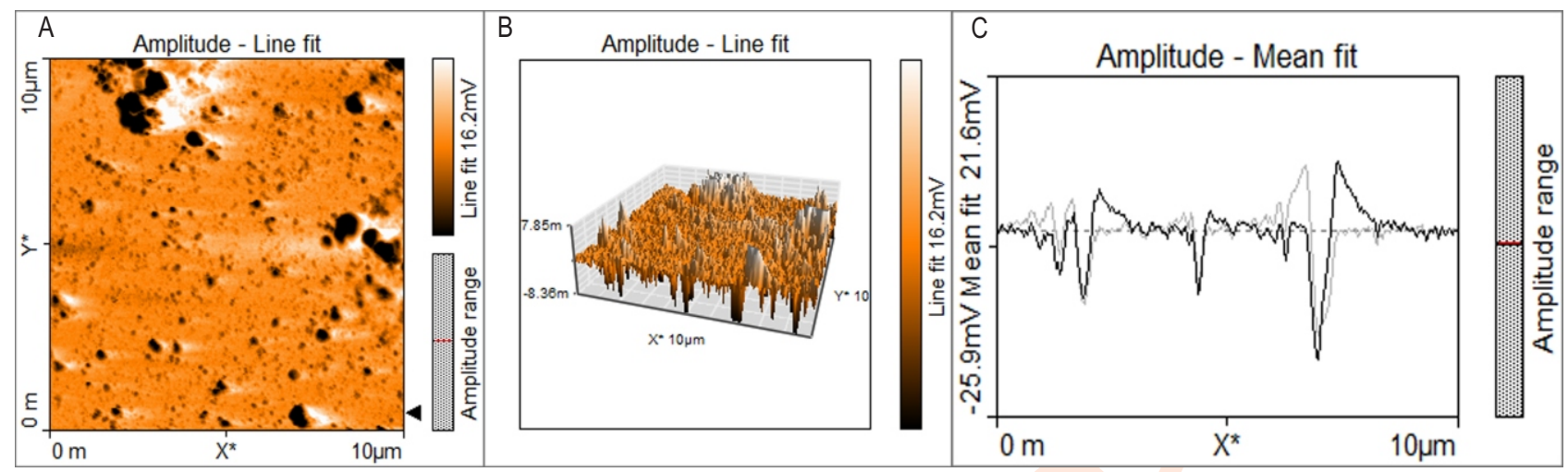

Fig. 3: AFM analysis of Panibacillus sp. NS-36 mediated AgNPs: (A) 2D structure of NS-36 AgNPs; (B) 3D structure of NS-36 AgNPs and (C) Particle size distribution of NS-36 AgNPs.
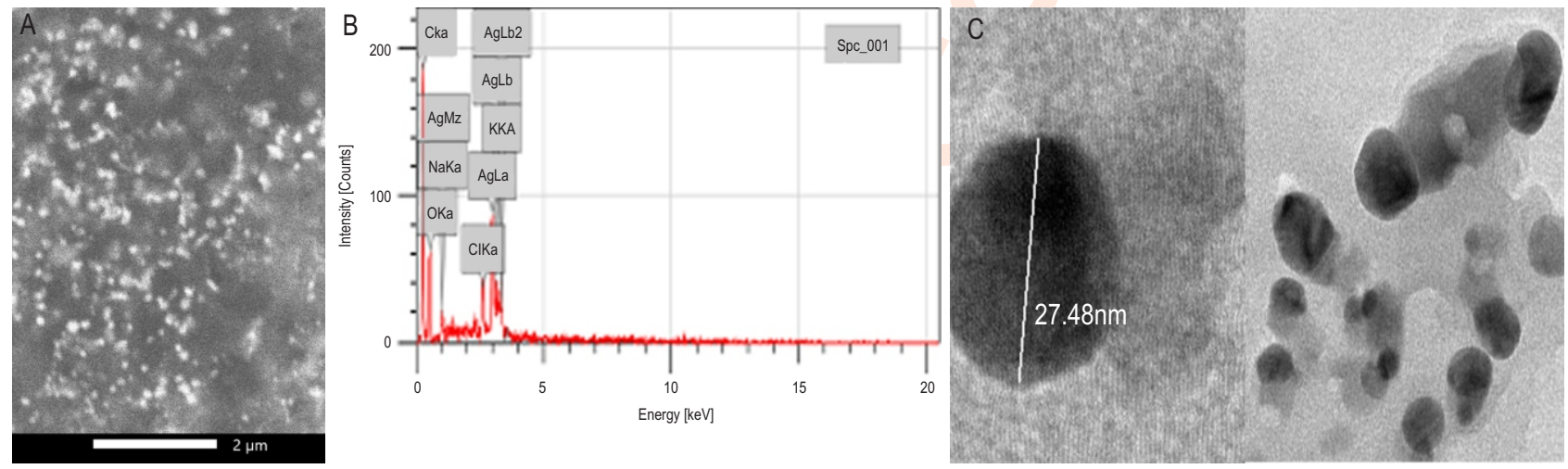

Fig. 4: Characterization of Panibacillus sp. NS-36 mediated AgNPs: (A) SEM analysis of NS-36 AgNPs; (B) EDX analysis of NS-36 AgNPs and (C) TEM micrograph of NS-36AgNPs.

36 strain at various magnifications confirmed the shape of AgNPs as spherical, size ranging between 17.49 to $52.85 \mathrm{~nm}$, with average size of $27.48 \mathrm{~nm}$ (Fig. 4C). In a similar study, Kalishwarlal et al. (2010) reported that the synthesized AgNPs were spherical, well dispersed and the size averaged at $50 \mathrm{~nm}$ with a uniform diameter. Recently, Dhanaraj et al. (2020) and Rajoka et al. (2020) reported that the synthesized AgNPs were spherical with size ranging from 10 to $100 \mathrm{~nm}$ with average size around $45 \mathrm{~nm}$.

The synthesized AgNPs showed good antibacterial activity against the selected pathogenic bacteria (Fig. 5A-D). Among the bacterial pathogens, E. faecalis was found to be more sensitive to AgNPs synthesized from the isolate Paenibacillus sp. strain NS-36, while $S$. pneumoniae was found to be least sensitive and Fig. 5E representing histogram of inhibition zone. The AgNPs showed formation of moderate inhibition zones on $S$. aureus and $E$. coli. The size and high surface area of AgNPs play an important role by enabling them to reach easily the nuclear content of bacteria to exhibit relatively high antibacterial activity
(Yurtluk et al., 2018). Similar reports have been documented by Elsayed et al. (2018) and Sowmya et al. (2019) suggested that AgNPs exhibit antibacterial activity by releasing $\mathrm{Ag}^{+}$ions, which gets attached to the surface of bacterial cell membrane and may disrupt membrane permeability, DNA replication, induce ROS and subsequently leading to bacterial cell death.

The morphological changes of Human colon adenocarcinoma HCT 116 cell line on adding different concentrations of AgNPs were recorded using an inverted phasecontrast tissue culture microscope (Fig. 6A-G). The results of negative and positive controls are depicted in Fig. 6A, B respectively. The changes in the morphology of cells, such as rounding or shrinking of cells at varying degree were visible in the images and it was a clear indication of cytotoxicity. In this study, the cytotoxicity was evaluated on HCT 116 cells in-vitro by MTT assay. About $50 \%$ of HCT 116 cells died when treated with AgNPs at concentrations between 12.5 to $200 \mu_{\mathrm{g} \mathrm{m}}{ }^{-1}$ (Fig. 6C-G). The observations of cell cytotoxicity study by ELISA reader suggested 

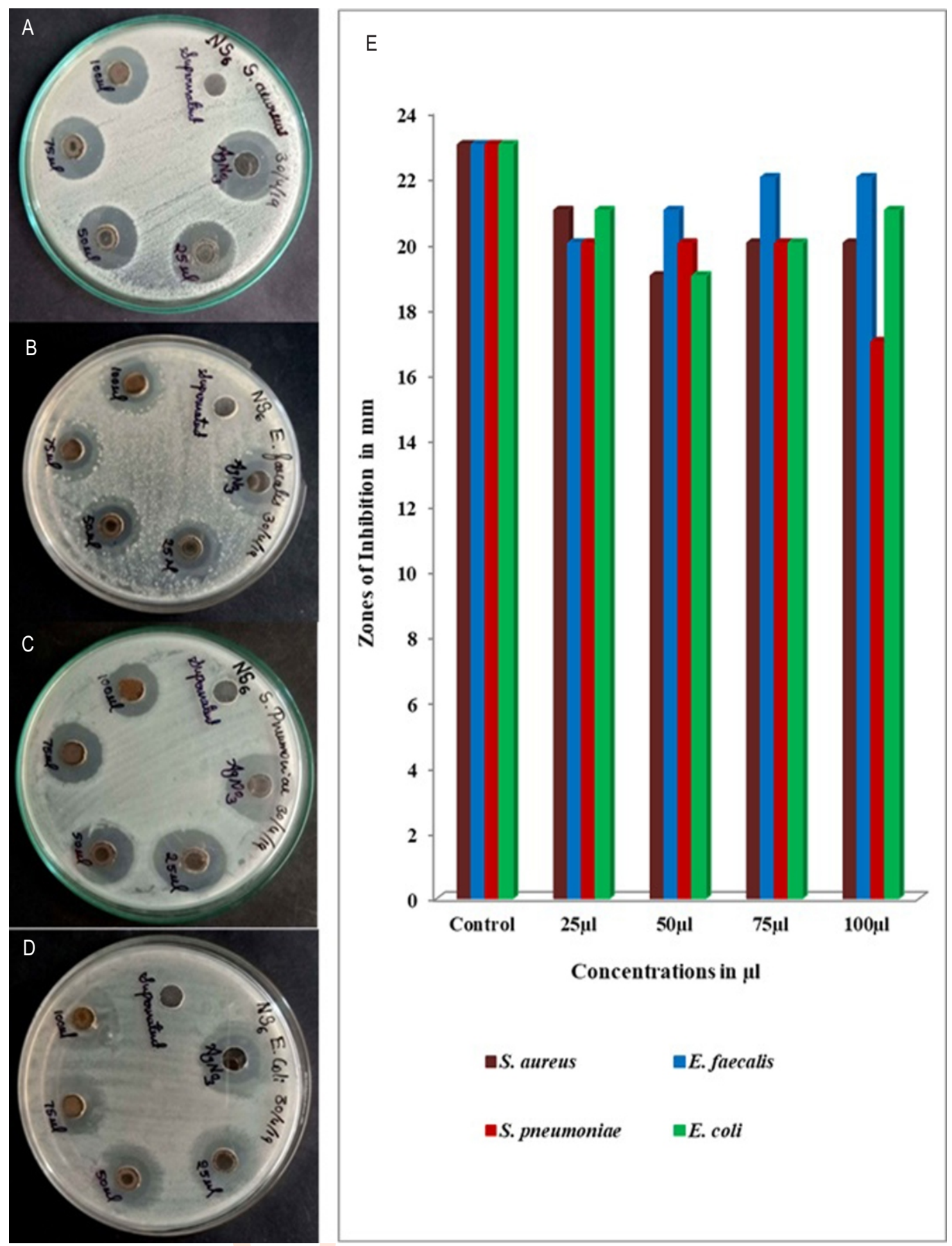

Fig. 5: Antibacterial activity of Panibacillus sp. NS-36 mediated AgNPs against bacterial pathogens: (A) S. aureus; (B) E. faecalis; (C) S. pneumoniae; (D) E. coliand (E) Histogram of zone of inhibition.

that AgNPs from Paenibacillus sp. strain NS-36 showed $\mathrm{IC}_{50}$ concentration at $81.45 \mu \mathrm{g} \mathrm{ml}^{-1}$ against HCT-116 cell line. The results suggests that the test compound may have good cytotoxic potential against HCT-116 cells, and the effect of AgNPs on the viability percentage of HCT-116 cell line showed a dose-dependent activity. Ramalingam et al. (2014) reported that very low concentration of AgNPs showed high activity i.e., $80 \%$ inhibition on MCF-7 cells. At higher concentration (10-100 $\left.\mu \mathrm{g} \mathrm{ml}^{-1}\right)$, no significant difference in the prevention of cancer cell growth was observed with AgNPs and $\mathrm{IC}_{50}$ value for AgNPs $>10$ 


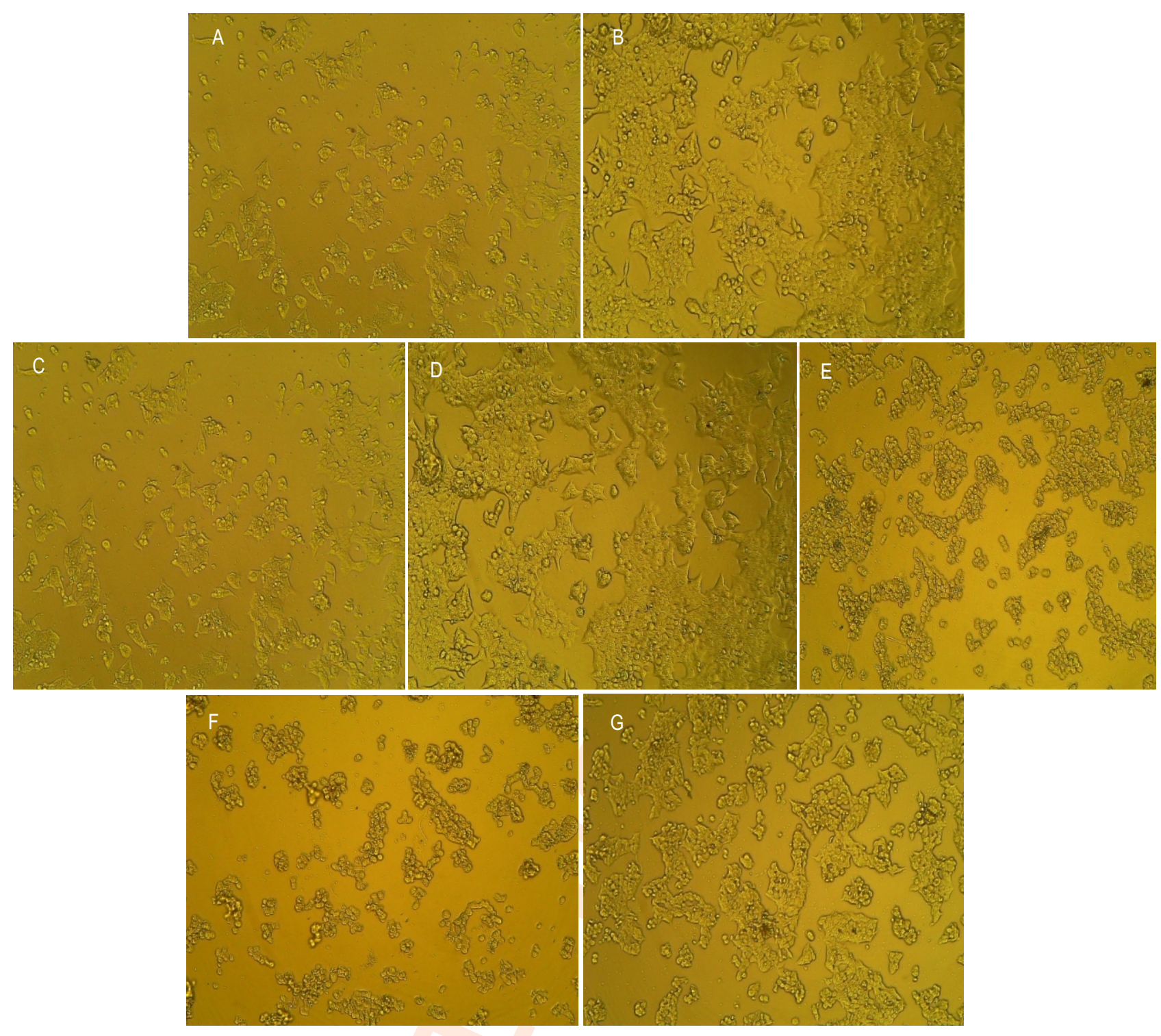

Fig. 6: Anticancer activity of Panibacillus sp. NS-36 mediated AgNPs at different concentrations against HCT-116 cell line: (A) Negative control

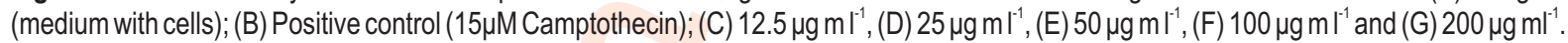

$\mu \mathrm{gl}^{-1}$. Also, Buttacavoli et al. (2018) and Siddiqi et al. (2018) found that HT-3, HT-29, HCT-116, SKBR3, 8701-BC and Caco2 cells were the most sensitive cancer cell lines when studied with the cytotoxic activity of AgNPs. Based on these findings, AgNPs may lead to valuable applications as antimicrobial agents in the medicinal field and it was also observed that anticancer activity of AgNPs induced intracellular ROS generation which caused cell damage. AgNPs are involved in the selective interruption of mitochondrial respiratory chain resulting in the production of ROS. These ROS species induce the expression of genes associated with DNA disruption and produces apoptosis of tumour cells (Bhatnagar et al., 2019; Priya et al., 2020; Ratan et al., 2020). Overall, the present work demonstrates an eco-friendly and low-cost synthesis procedure for AgNPs using the isolate Paenibacillus sp. strain NS-36. The results of this study provide useful information for designing a much better antibacterial and anticancer compound in the near future using bacterial mediated AgNPs.

\section{Acknowledgments}

The authors are grateful to the UGC-SAP-DSA-I, Department of Studies in Botany, Karnatak University, Dharwad for extending laboratory facilities. The authors are also thankful to the University Scientific and Instruments Centre (USIC), Karnatak University, Dharwad for providing instrumentation facilities. 


\section{Add-on Information}

Authors' contribution: N. Sreenivasa: Designed the concept, supervised and wrote the manuscript; B.P. Meghashyama: Wrote the manuscript and carried out experimental work; S.S. Pallavi, C. Bidhayak: Carried out experiments and edited the manuscript; A. Dattatraya, H. Halaswamy and S. B. Dhanyakumara: Edited manuscript and validated the data; $\mathbf{R}$. Muthuraj and K.N. Shashiraj: Edited manuscript and prepared figures/graphs; M.D. Vaishnavi: Carried out the laboratory work

Research content: The research contents is original and has not been published elsewhere

\section{Ethical approval: NotApplicable.}

Conflict of interest: The author declares that there is no conflict of interest.

\section{Data from other sources: NotApplicable}

Consent to publish: All authors agree to publish the paper in Journal of Environmental Biology.

\section{References}

Ahmad, R.S., M. Sara, R.S. Hamid, J. Hossein and N. Ashraf-Asadat: Rapid synthesis of silver nanoparticles using culture supernatants of Enterobacteria: Anovel biological approach. Process Biochem., 42, 919-923 (2007).

Ahmed, M.S., R. Soundhararajan, T. Akther, M. Kashif, J. Khan, M. Waseem and $\mathrm{H}$. Srinivasan: Biogenic AgNPs synthesized via endophytic bacteria and its biological applications. Environ. Sci. Pollut. Res., 26, 26939-26946 (2019).

Ahmed, R.H and D.E. Mustafa: Green synthesis of silver nanoparticles mediated by traditionally used medicinal plants in Sudan. Int. Nano Lett., 10, 1-14 (2019).

Akter, S. and M.A. Huq: Biologically rapid synthesis of silver nanoparticles by Sphingobium sp. MAH-11T and their antibacterial activity and mechanisms investigation against drug-resistant pathogenic microbes. Artif. Cells Nanomed. Biotechnol., 48, 672$682(2020)$

Ali, I., T.Y. Qiang, N. Ilahi, M. Adnan and S. Wasim: Green synthesis of silver nanoparticles by using bacterial extract and its antimicrobial activity against pathogens. Int. J. Biosci., 13, 1-15 (2018).

Allam, N.G., G.A. Ismail, W.M. El-Gemizy and M.A. Salem: Biosynthesis of silver nanoparticles by cell-free extracts from some bacteria species for dye removal from wastewater. Biotechnol. Lett., 41, 379-389 (2019).

Amdadul, H.M.: Green synthesis of silver nanoparticles using Pseudoduganella eburnea MAHUQ-39 and their antimicrobial mechanisms investigation against drug-resistant human pathogens. Int. J. Mol. Sci., 21, 1510-1518 (2020).

Ameen, F., S. Al-Yahia, M. Govarthanan, N. Al-jahadali, N. Al-Enazi, K. Alsamhari, W.M. Alshehi, S.S. Alwakeel and S.A. Alharbi: Soil bacteria Cupriavidus sp. mediates the extracellular synthesis of antibacterial silver nanoparticles. J. Mol. Struct., 1202, 127233 (2019).

Aw, Y.K., K.S. Ong, L.H. Lee, Y.L. Cheow, C.M. Yule and S.M. Lee: Newly isolated Paenibacillus tyrfis sp. nov., from Malaysian tropical peat swamp soil with broad spectrum antimicrobial activity. Front. Microbiol., 7, 219-227 (2016).

Bhatnagar, S., T. Kobori, D. Ganesh, K. Ogawa and H. Aoyagi: Biosynthesis of silver nanoparticles mediated by extracellular pigment from Talaromyces purpurogenus and their biomedical applications. Nanomaterials, 9, 1042-1061 (2019).

Biswas, A., C. Vanlalveni, P.P. Adhikari, R. Lalfakzuala and L. Rokhum: Biosynthesis, characterization and antibacterial activity Mikania micrantha leaf extract-mediated AgNPs. Micro Nano Lett., 14, 799$803(2019)$

Bray, F., J. Ferlay, I. Soerjomataram, R.L. Siegel, L.A. Torre and A. Jemal: Global cancer statistics 2018- GLOBOCAN estimates of incidence and mortality worldwide for 36 cancers in 185 countries. CA: CancerJ. Clin., 68, 394-424 (2018).

Burdusel, A.C., O. Gherasim, A.M. Grumezescu, L. Mogoanta, A. Ficai and E. Andronescu: Biomedical applications of silver nanoparticles: An up-to-date overview. Nanomaterials, 8, 681-706 (2018).

Burlacu, E., C. Tanase, N.A. Coman and L. Berta: A review of bark extract mediated green synthesis of metallic nanoparticles and their applications. Molecules, 24, 4354-4373 (2019).

Buttacavoli, M., N.N. Albanese, G. Di Cara, R. Alduina, C. Faleri, M. Gallo, G. Pizzolanti, G. Gallo, S. Feo, F. Baldi and P. Cancemi: Anticancer activity of bio generated silver nanoparticles: An integrated proteomic investigation. Oncotarget, 9, 9685-9705 (2018).

Deepika, H., L. Jacob, N.N. Mallikarjuna and S.V. Rajender: Greener techniques for the synthesis of silver nanoparticles using plant extracts, enzymes, bacteria, biodegradable polymers, and microwaves. ACS Sustainable Chem. Eng., 1, 703-712 (2013).

Dhanaraj, S., S. Thirunavukkarasu, H.A. John, S. Pandian, S.H. Salmen, A. Chinnathambi and S.A. Alharbi: Novel marine Nocardiopsis dassonvillei-DS013 mediated silver nanoparticles characterization and its bactericidal potential against clinical isolates. Saudi J. Biol. Sci., 27, 991-995 (2020).

Elsayed, M.A., A.M. Othman, M.M. Hassan and A.M. Elshafei: Optimization of silver nanoparticles biosynthesis mediated by Aspergillus niger NRC1731 through application of statistical methods- enhancement and characterization. 3 Biotech., 8, 132$141(2018)$

Girardin, H., C. Albagnac, C. Dargaignaratz, C. Nguyen-The and F. Carlin: Antimicrobial activity of foodborne Paenibacillus and Bacillus spp. against Clostridium botulinum. J. Food Prot., 65, 806$813(2002)$

Gnanakani, P.E., P. Santhanam, K. Premkumar, K.E. Kumar and M.D. Dhanaraju: Nanochloropsis extract-mediated synthesis of biogenic silver nanoparticles, characterization and in-vitro assessment of antimicrobial, antioxidant and cytotoxic activities. Asian Pac. J. Cancer Prev., 20, 2353-2364 (2019).

Gurunathan, S., K. Kalishwaralal, V. Ramanathan, V. Deepak, S.R.K. Pandian and M. Jeyaraj: Biosynthesis, purification and characterization of silver nanoparticles using Escherichia coli. Colloids Surf. B., 74, 328-335 (2009).

Hamouda, R.A., M.H. Hussein, R.A. Abo-elmagd and S.S. Bawazir: Synthesis and biological characterization of silver nanoparticles derived from the cyanobacterium Oscillatoria limnetica. RSCAdv., 9, 13071-13088 (2019)

Holt, J.G., N.R. Krieg, P.H.A. Sneath, J.T. Staley and S.T. Williams: Bergey's Manual of Determinative Bacteriology. $9^{\text {th }}$ Edn., Williams and Wilkins, Lippincott, pp. 307-308 (1994).

Hossain, A., X. Hong, E. Ibrahim, B. Li, G. Sun, Y. Meng, Y. Wang and Q. 
An: Green synthesis of silver nanoparticles with culture supernatant of a bacterium Pseudomonas rhodesiae and their antibacterial activity against soft rot pathogen Dickeya dadantii. Molecules, 24, 2303-2313 (2019).

Huang, E., X. Yang, L. Zhang, S.H. Moon and A.E. Yousef: New Paenibacillus strain produces a family of linear and cyclic antimicrobial lipopeptides; cyclization is not essential for their antimicrobial activity. FEMS Microbiol. Lett., 364, 1-6 (2017).

Kalishwaralal, K., V. Deepak, S.R.K. Pandian, M. Kottaisamy, B.M.K. Selvaraj and B. Kartikeyan: Biosynthesis of silver and gold nanoparticles using Brevibacterium casei. Colloids Surf. B, 77, 257-262 (2010).

Karthik, C. and K.V. Radha: Biosynthesis and characterization of silver nanoparticles using Enterobacter aerogenes: A kinetic approach. Dig. J. Nanomater. Biostruct., 7, 1007-1014 (2012).

Meenal, K. S. Sachin and A. Prakash: Biosynthesis of silver nanoparticles by marine bacterium Idiomarina sp. PR58-8. Bull. Mater. Sci., 35, 1201-1205 (2012).

Mouxing, F.U., L.I. Qingbiao, S.U.N. Daohua, L.U. Yinghu, H.E. Ning, D.E.N.G. Xu, W.A.N.G Huixuan and H.U.A.N.G Jiale: Rapid preparation process of silver nanoparticles by bioreduction and their characterizations. Chin. J. Chem. Eng., 14, 114-117 (2006).

Nadhe, S.B., R. Singh, S.A. Wadhwani and B.A. Chopade: Acinetobacter sp. mediated synthesis of AgNPs, its optimization, characterization and synergistic antifungal activity against $C$. albicans. J. Appl. Microbiol., 127, 445-458 (2019).

Nayak, S., M.P. Bhat, A.C. Udayashankar, T.R. Lakshmeesha, N. Geetha and S. Jogaiah: Biosynthesis and characterization of Dillenia indica-mediated silver nanoparticles and their biological activity. Appl. Organometal. Chem., 34, e5567 (2020).

Nayaka, S., C. Bidhayak, A. Dattatreya, B. Meghashyama, N. Shashiraj, S. Pallavi, R. Muthuraj, H. Halaswamy, B. Dhanyakumara and R. Maria: In-vitro antimicrobial activity of biological synthesized silver nanoparticles using Stenotrophomonas maltophilia strain NS-24 from non- rhizosphere soil. Int. J. Pharm. Pharm. Sci., 12, 73-79 (2020).

Pajor, M., Z.R. Xiong, R.W. Worobo and P. Szweda: Paenibacillus alvei MP1 as a producer of proteinaceous compound with activity against important human pathogens, including Staphylococcus aureus and Listeria monocytogenes. Pathogens, 9, 319-335 (2020).

Piuri, M., C. Sanchez-Rivas and S.M. Ruzal: Anovel antimicrobial activity of a Paenibacillus polymyxa strain isolated from regional fermented sausages. Lett. Appl. Microbiol., 27, 9-13 (1998).

Priya, K., M. Vijayakumar and B. Janani: Chitosan-mediated synthesis of biogenic silver nanoparticles (AgNPs), nanoparticle characterisation and in-vitro assessment of anticancer activity in human hepatocellular carcinoma HepG2 cells. Int. J. Biol. Macromol., 149, 844-852 (2020).

Ramalingam, V., R. Rajaram, C. Premkumar, P. Santhanam, P. Dhinesh, S. Vinothkumar and K. Kaleshkumar: Biosynthesis of silver nanoparticles from deep-sea bacterium Pseudomonas aeruginosa JQ989348 for antimicrobial, antibiofilm, and cytotoxic activity. J. Basic Microbiol., 54, 928-936 (2014).

Ratan, Z.A., M.F. Haidere, M. Nurunnabi, S.M. Shahriar, A.J.S. Ahammad, Y.Y. Shim, M.J.T. Reaney and J.Y. Cho: Green chemistry synthesis of silver nanoparticles and their potential anticancer effects. Cancers, 12, 855-880 (2020).

Rajoka, M.S.R., H.M. Mehwish, H. Zhang, M. Ashraf, H. Fang, X. Zeng, Y. Wu, M. Khurshid, L. Zhao and Z. He: Antibacterial and antioxidant activity of exopolysaccharide mediated silver nanoparticle synthesized by Lactobacillus brevis isolated from Chinese koumiss. Colloids Surf. B., 186, 110734-110744 (2020).

Roy, A., O. Bulut, S. Some, A.K. Mandal and M.D. Yilmaz: Green synthesis of silver nanoparticles: Biomolecule-nanoparticle organizations targeting antimicrobial activity. RSC Adv., 9, 2673 2703 (2019).

Sadowski, Z., I. Maliszweska, I. Polowczyk and T. Kozlecki: Synthesis of silver nanoparticles using microorganisms. Mater. Sci. Poland, 26, 419-424 (2008).

Saravanan, M., S.K. Barik, D.M. Ali, P. Prakash and A. Pugazhendhi: Synthesis of silver nanoparticles from Bacillus brevis (NCIM 2533) and their antibacterial activity against pathogenic bacteria. Microb. Pathogen., 116, 221-226 (2018).

Sekiguchi, Y., Y. Kamagata, K. Syutsubo, A. Ohashi, H. Harada and K. Nakamura: Phylogenetic diversity of mesophilic and thermophilic granular sludges determined by 16S rRNA gene analysis. Microbiology, 144, 2655-2665 (1998).

Shivaji, S., S. Madhu and S. Singh: Extracellular synthesis of antibacterial silver nanoparticles using psychrophilic bacteria. Process Biochem., 46, 1800-1807 (2011).

Siddiqi, K.S., A. Husen and R.A.K. Rifaqat: A review on biosynthesis of silver nanoparticles and their biocidal properties. J. Nanobiotechnol., 16, 1-28 (2018).

Singh, H., J. Du, P. Singh and T.H. Yi: Extracellular synthesis of silver nanoparticles by Pseudomonas sp. THG-LS1.4 and their antimicrobial applications. J. Pharm. Anal., 8, 258-264 (2018).

Sowmya, B., K.S. Venkat, S. Karpagambigai, R.S. Jacquline, J.S. Kumar and S. Rajesh Kumar: Antioxidant and antifungal activity of bacteria mediated silver nanoparticles using Rhizobium sp. Indian J. Pub. Hlth. Res. Dev., 10, 3622-3632 (2019).

Srivastava, S.K. and M. Constanti: Room temperature biogenic synthesis of multiple nanoparticles (Ag, Pd, Fe, Rh, Ni, Ru, Pt, Co, and Li) by Pseudomonas aeruginosa SM1. J. Nanopart. Res., 14, 831-840 (2012).

Tamura, K., S. Kumar and G. Stecher: MEGA7: Molecular evolutionary genetics analysis version 7.0 for bigger datasets. Mol. Biol. Evol., 33, 1870-1874 (2015).

Yurtluk, T., F.A.Akcay and A. Avci: Biosynthesis of silver nanoparticles using novel Bacillus sp. Prep. Biochem. Biotechnol., 48, 151-159 (2018).

Zhang, Y., J. Ren, W. Wang, B. Chen, E. Li and S. Chen: Siderophore and indolic acid production by Paenibacillus triticisoli BJ-18 and their plant growth-promoting and antimicrobe abilities. Peer J., 8, 1-26 (2020). 